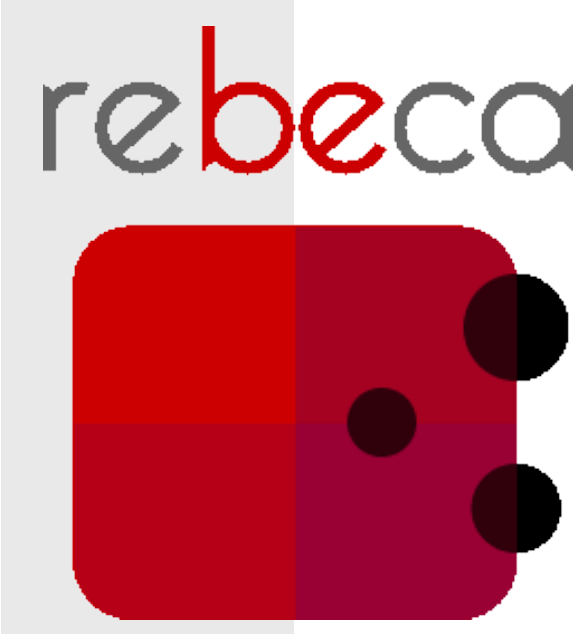

\title{
Gustavo Dahl: ideário de uma trajetória no cinema brasileiro
}

Entrevista concedida por Gustavo Dahl a Arthur Autran'

1. Professor junto à Universidade Federal de São Carlos. Publicou o livro Alex Viany: crítico e historiador e colaborou na Enciclopédia do cinema brasileiro (org. Fernão Ramos e Luiz Felipe Miranda), bem como nas coletâneas Documentário no Brasil: tradição e transformação (org. Francisco Elinaldo Teixeira) e Cinema e mercado (org. Alessandra Meleiro). Tem artigos publicados em periódicos como Alceu, Revista USP e Significação. Dirigiu os documentarios Minoria absoluta e A política do cinema. E-mail: autran@ufscar.br 
Gustavo Dahl (1938-2011) foi um dos mais importantes e ativos pensadores da história do cinema brasileiro nos últimos 50 anos. Herdeiro direto do pensamento do seminal crítico Paulo Emílio Salles Gomes, Dahl também se revelou um integrante importante da geração do Cinema Novo. Tanto a sua trajetória pessoal quanto a profissional se alicerçaram em uma carreira que transitou entre a crítica, a produção, a distribuição e a política do audiovisual nacional.

Gustavo Dahl teve iniciação cinematográfica no cineclube Dom Vital; depois, passou por instituições como Cinemateca Brasileira, Centro Sperimentale del Cinema, Embrafilme, Concine, Abraci, CBC, Ancine, CTAv etc. Além de envolver-se na produção de filmes de curta, média e longa metragens, nos quais exerceu várias funções - como produtor, roteirista, diretor, montador etc. Creio que sejam raras as personalidades na cultura brasileira, de um modo geral, que tenham cumprido tal trajetória com tanta desenvoltura, talento, denodo e honestidade de princípios.

Nesse longo caminho de dedicação ao cinema brasileiro, Gustavo Dahl teve a oportunidade histórica de acompanhar e participar das principais transformações no campo. Dahl deixou registrado o seu legado filosóficoartístico, que pode ser visto em seus filmes, depoimentos, textos etc. Materiais estes que se encontram corporificados nos mais diversos gêneros e suportes, tais como críticas, roteiros, filmes, depoimentos, debates, cartas, documentos governamentais, textos corporativos, manifestos, entrevistas, entre outros. Uma compilação preliminar dessa ampla obra resulta num acervo de mais de 200 escritos, que se encontram disseminados em revistas, folhetos, catálogos, jornais, livros nacionais, livros estrangeiros etc. Isso sem falar dos filmes e de um legado imaterial de difícil dimensionamento. De uma maneira geral, os 
seus trabalhos enfocam os problemas mais cruciais que afeta(ra)m a questão da afirmação de uma verdadeira indústria audiovisual brasileira. Mas, para além das controvérsias que derivaram das suas posturas e, consequentemente, dos erros e acertos dos seus prognósticos, deve-se destacar o estilo literário e libertário de Dahl. Além disso, destacam-se a sua enorme capacidade de concatenação e de raciocínio, na qual se conjugam elementos da cultura tradicional e contemporânea.

O material integrante desta Seção de Entrevistas é um marco inaugural da Rebeca. O presente texto foi originalmente preparado pelo Prof. Dr. Arthur Autran (UFSCar) e se encontra parcialmente veiculado no filme Cinema e política (2011). Trata-se do último depoimento de fôlego do bravo guerreiro, que nos deixou de maneira súbita em junho de 2011. A entrevista abaixo aconteceu no dia 24 de julho de 2010, na cidade do Rio de Janeiro, em seu refúgio no cinematográfico bairro de Santa Tereza.

Nesta entrevista, Gustavo Dahl nos relata com detalhes inéditos os principais fatos que afetaram e determinaram a política do cinema brasileiro nas duas últimas décadas. Há um desvelamento das ações que redundaram no fim da Embrafilme. Além disso, Dahl relata os bastidores do surgimento do Congresso Brasileiro de Cinema, o debate interno no Gedic e a construção do movimento que levou à criação da Ancine. 


\section{A Embrafilme e o cinema brasileiro}

\section{Arthur Autran:}

O que eu vou te pedir é para comentar, ao teu ver, quais são as razões do final do ciclo da Embrafilme.

\section{Gustavo Dahl:}

O final da Embrafilme, em 1990, eu acompanhei de um lado como cineasta, como agente da cena, mas acompanhei também como intervenção política. Isto porque na candidatura Collor houve uma situação na qual todo mundo caracterizava-o como candidato da direita. O meio cinematográfico inteiro caiu fazendo uma oposição ao Collor muito violenta. Eu me lembro de Cristina Pereira dizendo na televisão: "Vamos bater na bundinha desse moço" - e isso no segundo turno. Não se fala assim de um candidato a presidente da República. Eu me lembro também de uma entrevista na qual eu vi o Ipojuca Pontes apoiando o Collor. Aí, pode-se dar uma situação na qual o Collor ganhe e não tenha outro interlocutor, senão o Ipojuca Pontes. Aí eu fiz uns artigos, colocando que o Collor ia dar uma ruptura. Foi quando fui chamado para participar de uma comissão que estaria reformulando o Ministério da Cultura. Agora, antes a Embrafilme já tinha uma crise. A Embrafilme estava, por algumas razões, que a gente pode analisar aqui, ela estava - a palavra que me ocorre é um pouco forte, mas é essa mesmo - é se desmilinguindo. Isso porque ela tinha perdido autoridade, é uma coisa que o Carlos Augusto Calil, que foi o diretorgeral da Embrafilme, dizia: “A Embrafilme é a Geni, aquela em que todo mundo joga pedra". A composição da diretoria da Embrafilme, a composição de poder dentro da Embrafilme dava muita força ao diretor-geral. Era uma diretoria-geral com uma diretoria de operações não comerciais, que se ocupava do cinema 
ano I número I

entrevista cultural, e a outra, de administração e finanças. Entretanto, quem fazia chover ou fazer sol, nas várias hortas, era o diretor-geral.

Às vezes, tinha um conselho, ou algumas coisas assim, que [se] consultava, mas na verdade quem decidia era o diretor-geral. E, isso criava uma situação muito fisiológica, fatalmente, e os pleitos eram atendidos, também, segundo o que se julgava a importância política de cada pessoa, a importância política dentro do cinema. Isso fez com que o problema que existe até hoje no cinema brasileiro - que é a questão dos resultados, de você trabalhar a partir dos resultados -, já houvesse esse clima de uma certa promiscuidade. Promiscuidade no sentido de que não havia seletividade, e o cinema é uma coisa que você tem duas aferições de resultados muito claras: uma é a do resultado de bilheteria e a outra é a do reconhecimento. Se você dilui esses dois resultados, era um pouco o que acontecia, a instituição se desinstitucionaliza. Ela virava uma palavra que se usa, até agora, que a classe cinematográfica acha absolutamente normal: balcão. Então, a Embrafilme é um balcão, mas este negócio aqui comanda a produção nacional de um país importante, e é tratada como se fosse um balcão, é um pouco de falta de solenidade. Mas, num certo sentido, exprimia o sentimento coletivo.

Por outro lado, quando o Collor entrou naquela campanha da caça aos marajás, o funcionalismo público era um dos alvos do Collor. E, dentro desse funcionalismo público, o funcionalismo do Rio de Janeiro, que, ainda em 1990, havia ecos de antes de 60, quando se fundou Brasília, e até hoje o Rio sente em sua composição de funcionalismo os ecos do velho funcionalismo de antes da fundação de Brasília. Havia um clima que dizia: “Não, precisa mudar tudo...", e um dos alvos do governo Collor era a Embrafilme. Porque a Embrafilme tinha aquele folclore de dizer que os cineastas compravam apartamentos de cobertura na Vieira Souto. Paulo Francis dizia isso, a ideia de que havia mordomias incríveis. Na verdade, não havia, o que havia era uma certa apatia desse personalismo da escolha, uma certa indefinição, então essa imagem 
da Embrafilme se espalhava. É escandaloso dizer isso, mas, na verdade, a Embrafilme foi forte durante a ditadura militar. Isso porque ela correspondia ao modelo geiseliano de organização nacionalista, de organização da economia que é: empresa estatal, reserva de mercado e órgão regulador. Para garantir o mercado havia a Embrafilme, e o Concine, por sua vez, garantindo a reserva de mercado. É preciso entender um pouco essa estrutura da Embrafilme para a gente ver como terminou. Teve um momento em que a Embrafilme obteve uma grande atuação na distribuição, pois ela conseguiu ser a segunda distribuidora do país e exclusivamente com filmes brasileiros. Mas isso, digamos, até 80, 85. Depois, a própria distribuidora começou a passar por alterações, ela era uma atividade muito finalística, digamos assim, é uma atividade de comercialização, o nome da superintendência era "de comercialização", então você colocar uma coisa tão ágil e tão ligada à respostas imediatas como a distribuição dentro de uma estrutura estatal, e isso pode funcionar como funcionou determinado tempo, mas pode também perder a produtividade. Agora, digamos assim, imagina se você tivesse uma agência de publicidade feita dentro do serviço público, só dando esse exemplo. O que eu quero dizer é o seguinte: a Embrafilme tinha perdido autoridade, de um lado. O governo Collor queria, como fez: reduziu o status da Cultura . Por outro lado, havia a obsessão do mercado, que é uma visão extremamente primitiva de como funcionam os cinemas nacionais. Porque isso é realmente não entender as relações dos cinemas nacionais com o cinema americano. Eu não acho que o mercado seja um fator que não deve ser considerado dentro de uma atividade econômica e cultural como é o cinema, mas você tem que saber como é que rola o mercado no mundo. Saber que há uma diferença de escala e que cinemas nacionais, como o cinema brasileiro, não podem ser jogados no mercado simplesmente baseados na competição econômica com a grande indústria americana. Mas isso não era percebido, então a ideia era que os filmes que se viabilizassem, teriam que se viabilizar no mercado. "O Estado não tem que ficar alimentando esses parasitas", "a teta da Embrafilme", esse era o clima. Por outro lado, eu devo dizer que o cinema 
ano I número I

entrevista

brasileiro, como sempre, faz o possível para corresponder à imagem negativa que a sociedade tem dele. Cinema é uma coisa que se faz com dinheiro dos outros, até em Hollywood, no fundo tem um banco que financia. Você imagina o que é fazer com o dinheiro dos outros, do governo? Isso até se insere dentro da grande tradição patrimonialista da sociedade brasileira, teve décadas nas quais uma família abastada de Santa Catarina vivia da subvenção que o Estado brasileiro dava a ela. Isso porque eles tinham uma mina de carvão mineral em Santa Catarina. E, com isso, o Brasil podia fingir que tinha carvão mineral. Durante muito tempo, a classe dominante brasileira viveu do governo - estou falando em ciclos mais amplos. A gente pode começar desde a República Velha, no início do século, até Juscelino Kubitscheck. Então, essa tradição de depender do Estado (se você quiser recuar no tempo, você vai até D. João VI), de depender da corte, cria uma deformação profissional, uma relação profissional na qual você troca apoio político por benefícios. Portanto, você colocar tudo na dependência do governo cria as deformações que os economistas falam: da economia subsidiada, ou seja, o cinema era uma coisa que ainda não tinha ciclo econômico. Assim, ia se criando esse ambiente, ao mesmo tempo que ninguém ousava criticar a Embrafilme, propor um modelo, submetê-la a um crivo de racionalidade, meritocracia, eficiência, ninguém ousava criticar porque, se criticasse, não levava o seu. E isso também dava ao diretor da Embrafilme a sensação de não ter compromissos além daqueles que ele mesmo se impunha. O resultado que eu atribuo hoje é uma certa desinstitucionalização. A situação tendia à fisiologia. E, também, a situação do cinema foi mudando no Brasil. O número de salas foi diminuindo a partir de 1980 a 1985, o cinema brasileiro - que tinha tido um boom ali, de 1975 a 1985 - começou a perder o clima de grandes sucessos. O público começou a diminuir, a entrada começou a subir, a situação do cinema se complicou. O que acontece, ao mesmo tempo, é que a quantidade de cineastas ia aumentando. Porque é aquela coisa, tem sempre muitos debutantes; o modelo francês que é o de financiar $50 \%$ de cineastas novos por ano, ia fazendo com que a massa de cineastas fosse crescendo. Então 
o bolo tinha que ser dividido cada vez em fatias menores, por mais gente, e também tinha muito - a situação clássica - muitas pessoas que eram excluídas, não dava pra contemplar todo mundo. Aí começou, na classe cinematográfica, a haver um descontentamento com a Embrafilme. Resumindo numa frase grossa, mas o sentimento que pairava, era: “A Embrafilme é uma m...”. É engraçado esse nível. Então, havia uma desvalorização da empresa pelo lado dos cineastas. Essa desvalorização, evidentemente, passava para a mídia, para a sociedade. Ela chegava no governo e, de repente, ficava bem acabar com a Embrafilme.

\section{novo estado das coisas}

\section{Arthur Autran:}

Acho que você cobriu bem esse quadro do fim da Embrafilme. Dando um pulo no tempo, perguntando a tua visão: como surgiu a Subcomissão de Cinema do Senado Federal?

\section{Gustavo Dahl:}

A Subcomissão de Cinema do Senado foi criada como uma comissão provisória pelo Francelino Pereira. Eu não me lembro sob que pretexto, mas eu acho que o Francelino fez um discurso sobre o cinema brasileiro e propôs a criação de uma comissão, e quem passou a secretariar essa comissão era um assessor dele, João da Silveira, que era jornalista e também sociólogo e que percebeu que era uma coisa que podia ter importância. O Francelino percebeu que é uma coisa que dava mídia, porque o cinema tem essa capacidade, o cinema dá mídia. O cinema vai para manchete, o cinema ocupa um lugar no imaginário das pessoas. Aí essa comissão começou a colher depoimentos. E, como sempre, o cinema precisa de 
ano I número I

entrevista

intervenções no nível executivo, judiciário e legislativo. O Legislativo percebeu que teria um papel a jogar ali no Senado, e essa subcomissão, que estava dentro da Comissão de Educação, transformou-se, depois, em permanente. E também essa questão do deslocamento da interlocução do Poder Executivo para uma interlocução com o Poder Legislativo era uma coisa nova em cinema. Isso porque no Poder Legislativo você não chega com um "me dá um dinheiro aí”, tira com um roteirinho no bolso, "tá aqui meu roteiro, dá pra financiar?". Não, você tem que estabelecer leis, mecanismos de incentivo, é importante, mas não há benefícios diretos na ação legislativa, ela é mais politizada, mais institucionalizada.

Congresso Brasileiro de Cinema: politizando a corporação

Arthur Autran:

Comente a ação em torno do Congresso Brasileiro de Cinema, o terceiro Congresso, principalmente, que você presidiu. Processo esse que você mesmo chamou, em artigos na época, de processo de repolitização do cinema brasileiro.

\section{Gustavo Dahl:}

A questão do terceiro Congresso Brasileiro de Cinema começou com essa crise institucional e econômica. Eu ouso dizer crise cultural, também, na medida em que eu acho que a relação com o público do mercado interno é uma relação econômica, mas ela é também uma relação cultural e uma relação com imagem do país no exterior. Os filmes nos festivais têm a ver também, eles têm uma natureza cultural, então esta crise começou a criar de novo uma insatisfação, uma inquietação e um sentimento de que o modelo existente na 
época também não estava dando conta. Falando de modelo, voltando àquela questão do modelo da crise do final da Embrafilme. No governo Itamar Franco os cineastas conseguiram - liderados por Luís Carlos Barreto, que vinha trabalhando nisso há dez anos - fazer aprovar a Lei do Audiovisual, que era uma espécie de Lei Rouanet exclusivamente para o cinema. Ela trazia consigo uma vantagem extra, de que o sujeito deduzia o imposto de renda e ainda podia deduzir como despesa operacional. Simplificando muito, ele abatia 100\% do imposto de renda que seria 25\%, mas, além disso, ele podia abater isso também como despesa operacional. Então, ele abatendo como despesa, ele diminuía de novo seu imposto, então era um negócio para as empresas e isso criou um novo modelo. Mas esse próprio novo modelo também começou a fazer água. Isso porque ele implica um problema que existe até hoje: há uma indiscriminação na seleção dos filmes. Um sentimento de que o Ministério da Cultura não estava dando conta de administrar essa situação e de que fazia falta um órgão, uma instituição que se dedicasse ao cinema. Porque, depois da Embrafilme, o que ficou dentro do Ministério da Cultura foi uma Secretaria de Desenvolvimento Audiovisual, que, depois, virou a Secretaria do Audiovisual. Porém houve uma perda de status e uma perda de funcionários também: a Embrafilme tinha acho que 600 funcionários, mais ou menos, você tinha o Concine, que era um órgão regulador, de repente se fez o vácuo, o Ministério da Cultura de fato não dava conta. Então, a Fundação Cultural de Brasília decidiu fazer um seminário de cinema, convidou o Augusto Sevá, que me chamou pra fazer o seminário com ele. O tema do seminário era o velho tema de sempre: "O cinema brasileiro: Estado ou mercado?". Houve esse debate e, quando acabou, o Nilson, que depois foi ser diretor da Ancine, surgiu com a ideia de prolongar o negócio e fazer o congresso. A expressão repolitização do cinema brasileiro já tinha sido usada nas conclusões daquele seminário. O governo de Brasília estava sendo exercido pelo Christovam Buarque, que era do PT. O PT estava também com a prefeitura de Porto Alegre, e a prefeitura de Porto Alegre se interessou pela ideia de fazer uma coisa assim e decidiu levá-la pra frente. Aí convidaram o Roberto 
Farias, porque ele é uma liderança política importante do cinema brasileiro e, sobretudo, é o responsável pelo grande êxito da Embrafilme. Porque é engraçado que a Embrafilme passou de ser a Geni, aquela que leva pedrada de todo mundo, e depois, na medida que o tempo foi passando, as pessoas começaram a falar dos bons tempos da Embrafilme. Ela passou a ser o modelo. E como, além do fomento, do financiamento, tinha a atividade da distribuidora, então tinha um financiamento que era associado ao risco, e mesmo aquela fisiologia à qual eu havia me referido, ao diretor-geral, ela ainda tinha um nexo, como às vezes era exercida dentro do cinema. Ela ainda tinha uma certa orientação. Com a Lei Rouanet e a Lei do Audiovisual, o nível de decisão se diluiu inteiramente. Aí houve de novo uma situação parecida com o final da Embrafilme, onde a sociedade começou a criticar o modelo. Quando eu vi de repente no Jornal do Brasil um artigo de um sociólogo começando a esculhambar a Lei do Audiovisual, os cineastas, então pensei: "Se já começou o desmonte do modelo, é melhor que seja o próprio cinema brasileiro a presidir esse desmonte". Comecei a fazer uns artigos no Jornal do Brasil, onde coloquei a ideia de que não adiantavam ações utópicas. Era necessário ter uma visão sistêmica de que não adianta investir só em produção. Você tem que investir em produção, distribuição e em exibição, e, se bobear, você tem que investir em mídia, também, para conseguir. Senão a intervenção não se dá. Mas, voltando à repolitização: de um lado, esta crise no modelo; do outro, a insatisfação de novo. Eu tive o sentimento, assim como as pessoas que tinham uma certa consciência política dentro do cinema brasileiro e que intuíam que é um problema básico dentro do cinema brasileiro. Qual seja? Se você se apresentar dividido diante do governo, o governo diz: "Olha, eu até queria fazer, mas nem vocês se articulam". Aquela coisa que um candidato geral a direção da Embrafilme, como um presidente de uma entidade que senta numa máquina e diz: "Não, fulano não nos representa”. Aí vem a célebre frase do Eduardo Portela: "Dois cineastas fazem um partido". Portela foi ministro da Educação. Essa situação induzia a imaginar que era necessária uma grande composição política do cinema brasileiro. Teve também um precursor, que foi 
o Encine, que o Aloísio Raulino, então presidente da Apaci, e eu, presidente da Abraci, fizemos em São Paulo. Era um encontro de cinema sofisticadíssimo num hotel no bairro da Liberdade. Ao final do encontro, a ideia foi de botar na fotografia final todos os representantes das entidades inteiras que estavam lá. A ideia de uma federação de entidade, de trabalhar o consenso, de se apresentar unido diante do governo era uma coisa que estava latente. E, por outro lado, a repolitização era no sentido de dizer que, se você não explicar para a sociedade e para o governo brasileiro para que serve o cinema brasileiro, é complicado. Isso serve tanto para a sociedade quanto para o governo. O governo reage negativamente e a sociedade, que virou midiática, num certo sentido, também reage negativamente. Então, se você não tiver um papel ativo, você não vai ter reações nem da sociedade nem do governo. A ideia de repolitização era essa, e também de enfrentar uma coisa que o modelo das leis de incentivo fazem, que é o "bloco do eu sozinho" - hoje em dia nós estamos em situação acho que razoavelmente parecida, ou seja, a ideia do "bloco do eu sozinho". O individualismo exacerbado e as críticas a um projeto coletivo, a desautorização do projeto coletivo nos anos 1980 e 1990, desautorizaram também a participação do Estado. Aí era necessário promover um debate, uma articulação de todo mundo, e a resposta a essa convocação foi muito ampla. Eu me lembro de que, no primeiro Congresso, havia 44 entidades representantes e havia um clima de entusiasmo. Existia também um clima de insatisfação com o Ministério da Cultura. Um dos primeiros tópicos das resoluções do Congresso - a primeira era manter o Congresso; a segunda era pedir ao governo a criação de um órgão institucional que tomasse conta desses todos aspectos. Não era refazer a Embrafilme. Era refazer um arcabouço institucional de empresa estatal de órgãos de regulação, em suma, que saísse desses espontaneísmo. A repolitização representava isso, e na verdade é uma consciência de que você não faz cinemas nacionais sem fazer políticas de cinemas nacionais. Glauber Rocha, nosso herói, grande político de comunicações, dizia: “A política cinematográfica é a forma mais refinada de política". Então, se a gente ampliar e entender isso como 
ano I número 1

entrevista

política de comunicações e imaginar figuras como o Glauber ou Paulo Emílio Salles Gomes (que na verdade eram grandes políticos de comunicação), e se a gente vê a importância que a comunicação, que o audiovisual ganhou com o desenvolvimento tecnológico no momento em que a gente está vivendo, dá pra entender a frase de Glauber. E, em suma, se isso é verdade, havia imperado essa necessidade de repolitização.

\section{O início da era do cinema agenciado}

\section{Arthur Autran:}

Comente o surgimento e estruturação da Ancine.

\section{Gustavo Dahl:}

Como sempre, é preciso ir aos prolegômenos, antes do próprio Congresso Brasileiro de Cinema. Eu havia proposto a criação de uma secretaria nacional de política de comunicações na Casa Civil. Panfletei essa proposta que estava no ambiente, e a ideia é que fosse um órgão só de planejamento estratégico, que não lidasse com dinheiro. Naquela época, o Weffort, ministro da Cultura, achou isso um abuso, uma audácia. Isso porque já era a sinalização de retirada de pelo menos parte do cinema do MinC. Depois, quando teve o $3^{\circ}$ Congresso Brasileiro de Cinema, com a sua repercussão o governo do presidente Fernando Henrique percebeu que havia uma certa inquietação na área e chamou por caminhos transversos o Cacá Diegues, que, por sua vez, procurou Luís Carlos Barreto dizendo que queria conversar. O presidente queria conversar sobre a situação do cinema. Os dois então disseram que precisavam ter um encontro com o presidente. Foi aí que começou a ser agendado esse encontro, e eu fui chamado 
para participar desse encontro como representante do CBC, como representante da massa. Eu brincava, dizendo: “Eu aqui estou fazendo papel de povo". E teve esse encontro com o Fernando Henrique, com o Weffort e o célebre Pedro Parente. Foi quando o Cacá colocou a necessidade da permanência da ação governamental, da continuidade da ação governamental. O Luís Carlos colocou a necessidade da ampliação dessa ação diante da relevância que a atividade estava tendo. Eu fiz duas colocações - digamos que tivesse 20 anos de Lei Rouanet - e disse uma coisa para o Fernando Henrique ("Fernando Henrique" era muita intimidade para um presidente da República): que há uma coisa de gênero, que nos últimos anos se investiram 500 milhões de dólares na produção, e não se investiram cinco em gestão. A outra coisa que eu disse para o Fernando Henrique é que eu acho que compete ao MinC fazer política industrial, e Fernando Henrique, que é inteligente, percebeu que aí havia uma armadilha ideológica e respondeu no ato: "Não, não compete". É preciso esclarecer a respeito dessa história de política industrial. Há um mal-entendido no Brasil: as pessoas não percebem a importância cultural de um meio de comunicação de massa como o cinema, da indústria cinematográfica, as pessoas falam muito da importância que o cinema tem para os Estados Unidos, mas não imaginam que a gente possa ter uma indústria de cinema no Brasil, coisa que pode. Então, Fernando Henrique passou para o Pedro Parente a tarefa de equacionar a questão, e assim se fez o Grupo Executivo de Desenvolvimento da Indústria do Cinema (Gedic), que começou a trabalhar dentro da Casa Civil. Mas a história do Gedic é uma outra história. Houve um momento em que eu percebi que aquela ação política dentro da Casa Civil estava se diluindo, e que, na hora de fazer, ficava dizendo que precisava de apoio, precisava de dinheiro, que o BNDES vai prover para fazer aquilo. Terminou o apoio ao Gedic sobrando para o MinC, que era exatamente o que a gente dizia que não estava dando conta. Aí, também, é aquela coisa, você cria os grupos de trabalho e, depois, as coisas se diluem. Eu percebi que estava havendo uma certa diluição das coisas. Fiz o que eu às vezes faço, tanto em crises pessoais quanto em crise política, que é 
ano I número I

entrevista

sentar na máquina e começar a escrever. Então, comecei a escrever o que terminou sendo o pré-relatório do Gedic e levei para o grupo e assim virei o relator. Mas depois houve contribuições nesse grupo do Gedic, onde estava Luís Severiano Ribeiro representando os exibidores, Rodrigo Santonino Braga representando os distribuidores, Evandro Guimarães representando a Globo e a televisão, Luís Carlos Barreto representando os produtores, Cacá Diegues representado os diretores. Era um grupo de peso e de gente com capacidade de pensar e de influir. E também teve contribuições do Rodrigo, do Luís Carlos e do Cacá ao relatório. Houve um momento, o grupo tinha seis meses para apresentar um resultado que foi prolongado por um ano, e, no meio da coisa toda, apareceu aquele pré-relatório. Eu disse ao Pedro Parente que precisava terminar o relatório, e que dentro do relatório havia a reivindicação de fazer uma proposta de agência que já tinha sido uma conversa minha com o Cacá uma vez no restaurante Celeiro, um restaurante vegetariano chique aqui do final do Leblon, chique não, elegante, de comida vegetariana, e Cacá disse que precisava fazer uma agência. Isso porque essa história começou com a ideia de uma ONG, depois eu transformei numa ideia de Secretaria Nacional de Política Cinematográfica e Audiovisual. O Cacá disse que precisava fazer uma agência. Então havia, de um lado, a pressão política do CCB, do outro, a proposta de se utilizar um modelo que estava muito em voga no governo FHC, que era o das agências. Então, quando foi se fazer o Gedic, a questão da agência já estava ali no bojo de medidas, numa instituição que agisse uma política. Então eu ali representando o grupo, chegou um momento em que eu disse para o Pedro Parente que a gente precisava terminar o relatório e ele me disse: "Gustavo, eu sou muito pragmático, esse negócio de relatório é interessante, mas vamos partir diretamente para a redação de uma medida provisória". Então, a Casa Civil chamou a Vera Zaverucha e, com a Tatiana Rosito, que era a assessora especial do Pedro Parente, começou a desenhar a medida provisória que criou a Ancine. Esta que, diga-se de passagem, foi a penúltima medida provisória do antigo regime de medidas provisórias que tinha, nas quais elas eram exaradas 
pela Presidência da República e não podiam ser modificadas pelo Congresso eram as chamadas medidas provisórias pétreas. Então começou a discussão da Ancine, e teve um momento no qual o Pedro Parente disse: "A gente precisava colocar a televisão nisso também". Sábio, Cacá disse: "Acho que é muita areia para o nosso caminhãozinho". O audacioso Luís Carlos Barreto disse: "Oba, a gente vai amarrar as camisas com a TV Globo”, aí vai ter a tal ampliação da atividade que ele queria. Eu, moderado, dizia: "Acho que não se pode tirar inteiramente a televisão, mas que é bom delimitar o campo". Mas então a coisa foi avançando, e dentro da medida provisória havia uma proposta de a televisão pegar uma porcentagem do faturamento da produção de publicidade para investir em produção, e também de criar um compromisso de que a televisão comprasse e exibisse o estoque histórico, é o que os franceses chamam de cahiérs du chargement, cadernos de obrigações. Isso é uma coisa que foi indo, até que teve um determinado momento em que o Evandro Guimarães sumiu da comissão, representando a Globo. Ele mandou um aviso dizendo que achava melhor ficar só com o cinema. Na hora em que a MP ia ser promulgada deu um revertério - conta a lenda que o Roberto Marinho desceu de helicóptero no Palácio do Planalto, pondo todas a televisões juntas. O ano era eleitoral, e chegaram para o Fernando Henrique e disseram: "Vamos tirar a televisão daí", que depois vai se repetir com a criação da Ancinav. Então se reduziu a coisa toda, passou a ser cinema e suporte videofonográfico. Mas aí foi criada a Ancine, a partir do nada. É uma coisa que, quando acabou, a Casa Civil disse: “Bem, Gustavo, agora a lei está pronta e você vai à luta". Eu fui designado por causa do papel que eu tinha tido ali no Gedic, fui indicado como diretor, presidente da Ancine. Aí, também, houve a questão das diretorias, na qual foi nomeado o João da Silveira, por conta da Subcomissão de Cinema do Senado, que o projeto tinha passado pelo Senado. Então o Francelino fez valer os seus direitos, Augusto Sevá vinha de uma representação paulista para retirar o monopólio do Cinema Novo da política cinematográfica que tinha feito desde os anos 60. Iria entrar a Vera Zaverucha, que já estava, mas aí rolou que 
terminaram botando a Lia Gomensoro, que era uma advogada do BNDES que estava muito perto de Pedro Parente. É interessante dizer que, durante esse período do Gedic, teve também o apagão. No meio do apagão, ligar para o Pedro Parente e dizer: "Vem cá, e a nossa Ancine, como é que vai?". Eu me sentia um pouco desproporcional, digamos assim. A Ancine começou, mas estava vinculada ao Ministério de Desenvolvimento de Indústria e Comércio, não primeiro à Casa Civil para se implantar e depois de um ano ir para o Ministério da Indústria e Comércio. 